\title{
Band gap blue shift of InGaAs/InP multiple quantum wells by different dielectric film coating and annealing
}

\author{
J. Zhao ${ }^{\text {a,* }}$, J. Chen ${ }^{\text {a }}$, Z.C. Feng ${ }^{\text {b }}$, J.L. Chen ${ }^{\text {c }}$, R. Liu ${ }^{\text {c }}$, G. Xu ${ }^{\text {d }}$ \\ ${ }^{a}$ College of Physics and Electronic Information Science, Tianjin Normal University, Tianjin 300074, PR China \\ ${ }^{\mathrm{b}}$ Graduate Institute of Electro-Optical Engineering and Department of Electrical Engineering, National Taiwan University, Taipei 106-17, Taiwan, ROC \\ ${ }^{c}$ Department of Physics, National University of Singapore, 119260 Singapore, Singapore \\ ${ }^{\mathrm{d}}$ Department of Materials Science and Engineering, McMaster University, Hamilton, Canada L8S $4 L 7$
}

Available online 29 August 2005

\begin{abstract}
Band gap blue shift of InGaAs/InP multiple quantum well (MQW) structures by impurity-free vacancy disordering (IFVD) is studied by photoluminescence (PL) and secondary ion mass spectrum (SIMS). $\mathrm{SiO}_{2}, \mathrm{Si}_{3} \mathrm{~N}_{4}$, and spin on glass (SOG) were used for the dielectric layers to create the vacancies. The results indicate that the band gap blue shift varies with the different dielectric layers and depends on the annealing temperature. The blue shift is also related to the combination of the layers between dielectric and cladding layers. The SIMS profile shows that the dielectric capped layer and rapid thermal annealing caused the quantum well intermixing, which results in the band gap blue shift. Optimum condition can be reached by choosing suitable dielectric layer and annealing condition.

(C) 2005 Elsevier B.V. All rights reserved.
\end{abstract}

Keywords: InP; InGaP; Molecular beam epitaxy; Quantum well; Impurity-free vacancy-enhanced intermixing; Dielectric cap; Rapid thermal annealing; SIMS; Optical properties

\section{Introduction}

Photonic and electronic integrated devices based on $\operatorname{InGaAs}(\mathrm{P}) / \mathrm{InP}$ multiple quantum well (MQW) structures are attracting much attention for optical communication system development [1-6]. Selective band gap tuning is crucial in fabricating these integrated photonic devices. For achieving this goal, different techniques are currently under investigation, including selective area growth and growthetch-regrowth. Regrowth requires many steps of etching and regrowth is often associated with low efficiency and poor yield [7]. Also, the contamination and defects at the etching and regrowth interface are difficult to avoid. Quantum well intermixing (QWI) technology has shown as a good way to achieve this purpose for high power semiconductor lasers and photonic integrated devices and

\footnotetext{
* Corresponding author. Tel.: +86 22 23540268; fax: +86 2223540278 E-mail address: jiezhao1943@126.com (J. Zhao).
}

circuits $[5,6,8]$. QWI is based upon the post-growth tuning of band gap energy of multi-quantum well (MQW) structures to avoid the complicated post growth processing. In order to realize the monolithic integration of active and passive optoelectronic devices and components, as an alternative approach, post growth QWI becomes a more attractive technique, which can change the QW shape and composition by intermixing wells and barriers in QWs and gives rise to a blue-shifted band gap. This post-growth control of QW profiles or the post-tuning of optical band gap energy can be realized by impurity-induced intermixing or impurity-free vacancy enhanced intermixing $[5,6,8,9]$. Several technical approaches have been explored to achieve this purpose, including impurity-induced disordering (IID) $[10,11]$, implant-induced composition disordering (IICD) $[7,12-14]$, and impurity-free vacancy disordering (IFVD) [7,15-17]. IID usually introduces some free carriers, which usually cause absorption. IICD creates some defects by ion implantation damaging the crystal quality and it also needs high energy implanter to perform the ion implantation for 
actual laser structure because of thick clapping layer. In comparison with IID and IICD, IFVD shows to be more promising because it can keep high crystal quality and low optical propagation loses as well as not introduce free carrier concentration. In the approach of IFVD, utilizing a dielectric layer as $\mathrm{Ga}$ sink at elevated temperature results in the redistribution of $\mathrm{Ga}$ vacancies in MQW structures to enhance quantum well intermixing [18,19]. So, IFVD is a simple effective approach to create band gap tailing without free carrier adsorption and damage of crystal lattice.

During the IFVD process, there usually involves a deposition of a dielectric capping layer such as $\mathrm{SiO}_{2}$ and $\mathrm{Si}_{3} \mathrm{~N}_{4}$ on the top of QWs and a rapid thermal annealing (RTA) at elevated temperature. Vacancies can be created at the dielectric-semiconductor interface due to the outdiffusion, for example, $\mathrm{Ga}$ atoms from the semiconductor layers into the dielectric region. The diffusion of these vacancies into the structure can enhance the $\mathrm{QW}$ intermixing, leading to a large blue shift of the QW band gap with minimum effect on their electrical and optical properties $[19,20]$. By using the IFVD technique, QW intermixing has been realized on multiple quantum well (MQW) structures of $\mathrm{InGaAs} / \mathrm{InP}$ [6,7,15], InGaAs/GaAs [16,17], AlGaAs/GaAs [16], InGaAs/InGaAsP [7], and InGaAsP/InGaAsP [21].

It is found that the choice, combination and properties of capping layers have important influence on the degree of QWI and band gap blue shifts. The $\mathrm{SiO}_{2}$ dielectric cap is porous to out-diffusion of $\mathrm{Ga}$ atoms, so generating group III vacancies that result in diffusion of Group III atoms from the barrier to the well [22]. As a result, effective band gap of the QW is widened. If the cap does not absorb significant $\mathrm{Ga}$ atoms, QWI is suppressed. For the GaAs-AlGaAs QW system, $\mathrm{SiO}_{2}$ cap has been generally used to promote QWI while $\mathrm{SiN}_{x}$ is used as a mask to prevent or suppress QWI because $\mathrm{SiO}_{2}$ cap layer induces a relatively larger blue shift than $\mathrm{SiN}_{x}$ cap layer [23]. A very thin $\mathrm{SiO}_{2}$ cap is also expected to suppress QWI because of saturation of Ga absorption [24].

For the InGaAs/InP system, $\mathrm{SiO}_{2}$ cap is also employed to enhance QWI while $\mathrm{Si}_{3} \mathrm{~N}_{4}, \mathrm{Ga}_{2} \mathrm{O}_{3}, \mathrm{P}: \mathrm{SiO}_{2}$, and $\mathrm{SrF}_{2}$ are used to suppress the intermixing [17]. By changing the deposition pressure of $\mathrm{SiO}_{x}$ capping layers, variable blue shifts can be obtained [17]. It is also reported for this system that the $\mathrm{SiO}_{2}-\mathrm{In}_{0.53} \mathrm{Ga}_{0.47} \mathrm{As}$ combination produces the band gap blue shift while $\mathrm{SiO}_{2}-\mathrm{InP}$ or $\mathrm{SiN}_{x}-\mathrm{InGaAs}$ cap layer combinations did not show significant energy shift [15]. The effect of semiconductor-capping layer combination on QWI for the $\operatorname{In}_{1-x} \mathrm{Ga}_{x} \mathrm{As} / \mathrm{In}_{1-x} \mathrm{Ga}_{x} \mathrm{As}_{1-y} \mathrm{P}_{y} \mathrm{MQW}$ structures showed similar trends [7]. The samples with the $\mathrm{InGaAs} / \mathrm{SiO}_{2}$ capping layer combination exhibited a higher degree of intermixing than those with the $\mathrm{InP} / \mathrm{SiO}_{2}$ capping layer combination after RTA treatment. This is attributed to the fact that InP has no $\mathrm{Ga}$ atom and possesses a lower thermal expansion coefficient than InGaAs [7].

However, the reliability and the mechanism of IFVD still need further investigation to meet the requirement of device processing. $\mathrm{SiO}_{2}$ and $\mathrm{Si}_{3} \mathrm{~N}_{4}$ as dielectric layer in IFVD have been reported in $\mathrm{AlGaAs} / \mathrm{GaAs}$ and $\mathrm{InGaAs} / \mathrm{InP}$ systems, respectively $[6,9]$. However, to our knowledge, there is no report on the comparison between these two dielectric and spin on glass (SOG) layer used in InGaAs/InP system.

In this paper, systematic investigation on band gap shift of InGaAs/InP system using $\mathrm{SiO}_{2}, \mathrm{Si}_{3} \mathrm{~N}_{4}$, and $\mathrm{SOG}$ as dielectric layers in IFVD is reported. The mechanism of the quantum well intermixing is discussed based on PL and SIMS analysis.

\section{Experimentals}

$\mathrm{In}_{0.65} \mathrm{Ga}_{0.35} \mathrm{As} / \mathrm{InP}$ lattice matched multi-quantum well (MQW) structures were grown by gas source molecular beam epitaxy (GSMBE). Four $7.5 \mathrm{~nm}$ InGaAs quantum wells separated by $10 \mathrm{~nm}$ InP barriers were grown on semiinsulating (SI) InP substrate and capped with $50 \mathrm{~nm} \mathrm{InP}$ layer which can allow the radiation from wells to penetrate through. Therefore this structure is suitable for PL study. The structure and the band gap are shown in Fig. 1.

All samples were cleaved into $2 \times 3 \mathrm{~mm}^{2}$ for PL measurements and $5 \times 6 \mathrm{~mm}^{2}$ for SIMS profile characterization. The samples were divided into three groups of capped dielectric layers of $\mathrm{SiO}_{2}, \mathrm{Si}_{3} \mathrm{~N}_{4}$ by plasma enhanced chemical vapour deposition (PECVD) and SOG (spin on glass) by spin coating at $3000 \mathrm{rpm}$ for $20 \mathrm{~s}$. The thickness of the dielectric layer in all samples is about $150 \mathrm{~nm}$. For the SOG capped samples were then backed at $350{ }^{\circ} \mathrm{C}$ for $2 \mathrm{~h}$ under pure nitrogen ambit protection.

The samples were then annealed in a rapid thermal annealing (RTA) furnace at the temperature range from 600 to $850^{\circ} \mathrm{C}$ in $50^{\circ} \mathrm{C}$ steps. The annealing time for all samples was kept for $10 \mathrm{~s}$ in accordance with our previous studies [6]. During the RTA the samples were covered with a piece of SI-GaAs face-to-face to minimize the decomposition of $\mathrm{InP}$ and possible contamination. All annealing processes are under pure nitrogen protection.

Photoluminescence (PL) measurements were performed at the temperature range from $10 \mathrm{~K}$ to $300 \mathrm{~K}$. The excitation source was an argon laser with the wavelength of $488 \mathrm{~nm}$. The secondary ion mass spectroscopy (SIMS) profile was carried out utilizing a SIMS instrument in mode of IMS-6F made in France. Cs ions were utilized as primary beam. In, $\mathrm{Ga}$, and As ions were detected at the depth by $\mathrm{Ar}^{+}$beam sputtering.

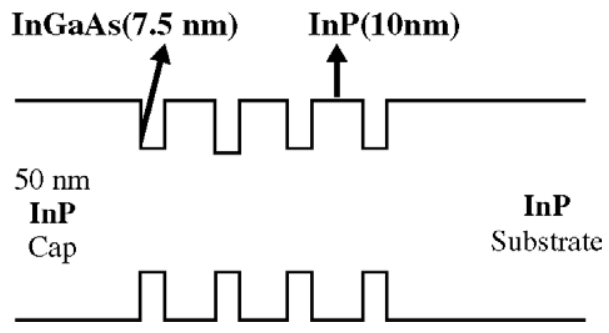

Fig. 1. The structure of experimental samples. 


\section{Results and discussion}

The results of PL spectra and SIMS characterization for the samples with three kinds of capped dielectric layer are discussed as follows.

\section{1. $\mathrm{Si}_{3} \mathrm{~N}_{4}$ covered sample}

The PL spectra of InGaAs/InP MQW structures capped with $\mathrm{Si}_{3} \mathrm{~N}_{4}$ and annealed at temperature of $800{ }^{\circ} \mathrm{C}$ for $10 \mathrm{~s}$ compared with the control sample and annealed only sample as well as those by $\mathrm{SiO}_{2}, \mathrm{Si}_{3} \mathrm{~N}_{4}$, and $\mathrm{SOG}$ covered IFVD are shown in Fig. 2. It can be observed that the PL peak of the sample coated with $\mathrm{Si}_{3} \mathrm{~N}_{4}$ annealed at $800{ }^{\circ} \mathrm{C}$ for $10 \mathrm{~s}$ shifts $16 \mathrm{meV}$ towards short wavelength. However, the PL peak of the sample without $\mathrm{Si}_{3} \mathrm{~N}_{4}$ capping shifts only $3 \mathrm{meV}$, indicating that the InGaAs/ InP structure at $800{ }^{\circ} \mathrm{C}$ is thermal stable and the $\mathrm{Si}_{3} \mathrm{~N}_{4}$ capping layer created some vacancies which result in the $\mathrm{Ga}$ and As redistribution. This quantum well intermixing caused the band gap blue shift.

In order to find the temperature dependence of band gap blue shift, the samples covered with $\mathrm{Si}_{3} \mathrm{~N}_{4}$ were annealed at temperatures of $600,650,700,750,800$, and $850{ }^{\circ} \mathrm{C}$, respectively. Fig. 3 shows the temperature dependence of band gap shift. It can be observed that the shift of PL peak increases with the rising of the RTA temperature. For low temperature range, $600-700{ }^{\circ} \mathrm{C}$, the PL peaks experienced only little change; however, when the annealing temperature went over $700{ }^{\circ} \mathrm{C}$, the PL peak moved to short wavelength evidently. At $750{ }^{\circ} \mathrm{C}$, it shifted $12 \mathrm{meV}$, at $800{ }^{\circ} \mathrm{C}$ it shifted $16 \mathrm{meV}$ and at $850{ }^{\circ} \mathrm{C}$, the blue shift reached $30 \mathrm{meV}$. However, the surface morphology at $850{ }^{\circ} \mathrm{C}$ became rusty due to the P-decomposition from InP. Taking account of this effect, annealing at $800{ }^{\circ} \mathrm{C}$ is probably the optimum condition under which $16 \mathrm{meV}$ blue shift can be obtained, and at the same time, the surface of the sample kept good quality morphology.

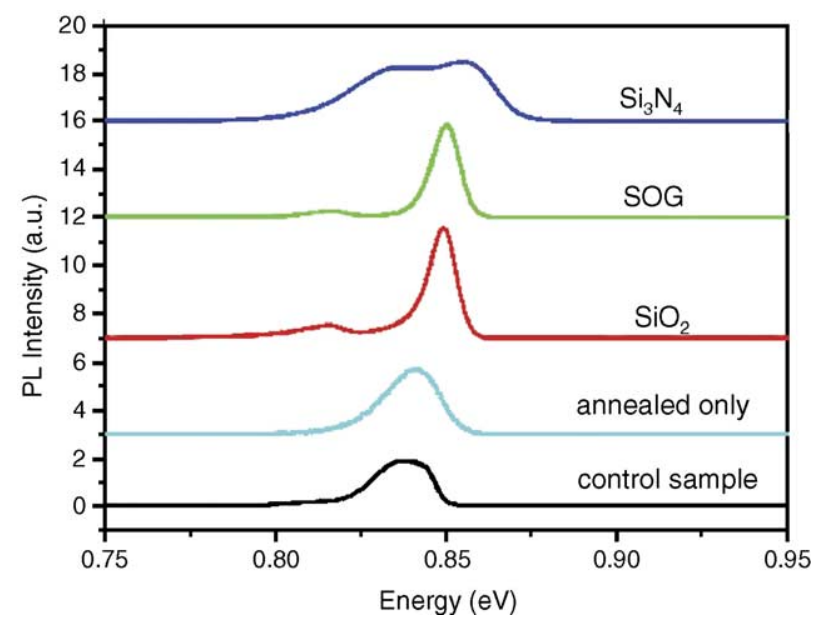

Fig. 2. The PL spectra of control sample and annealed only sample as well as those by $\mathrm{SiO}_{2}, \mathrm{Si}_{3} \mathrm{~N}_{4}$, and SOG covered IFVD.

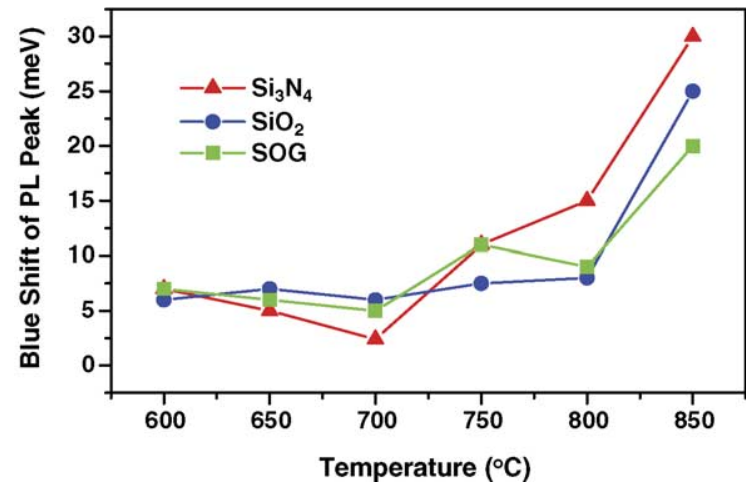

Fig. 3. The temperature dependence of blue shift for different dielectric covered samples.

The quantum well intermixing by IFVD can also be proved by high resolution SIMS profile measurement. Fig. 4 shows the SIMS profile of $\mathrm{Ga}$ and As ions from the control sample and the sample annealed at $800{ }^{\circ} \mathrm{C}$, respectively. It can be clearly observed that Ga and As diffused out of the quantum well region, especially towards the inside of the bulk. The distribution of $\mathrm{Ga}$ and As in quantum well region becomes smooth compared with the control sample. The SIMS profile for the sample annealed at lower temperature $\left(600-700{ }^{\circ} \mathrm{C}\right)$ is as close as the control sample, indicating there is no evident intermixing that happened at this temperature. It is consistent with the results of PL measurement above.

\section{2. $\mathrm{SiO}_{2}$ and $\mathrm{SOG}$ covered samples}

In comparison with $\mathrm{Si}_{3} \mathrm{~N}_{4}$ covered sample, the blue shifts of $\mathrm{SiO}_{2}$ covered sample and $\mathrm{SOG}$ covered sample are smaller than the $\mathrm{Si}_{3} \mathrm{~N}_{4}$ one. At $800{ }^{\circ} \mathrm{C}$, the blue shift of $\mathrm{SiO}_{2}$ covered sample is $9 \mathrm{meV}$ and the SOG covered sample is 10 $\mathrm{meV}$, respectively (Fig. 2). Fig. 3 also shows the band gap blue shift versus the annealing temperature for the three kinds of samples, indicating that the combination of InP cladding layer and the $\mathrm{Si}_{3} \mathrm{~N}_{4}$ dielectric layer can create more intermixing which caused more blue shit.

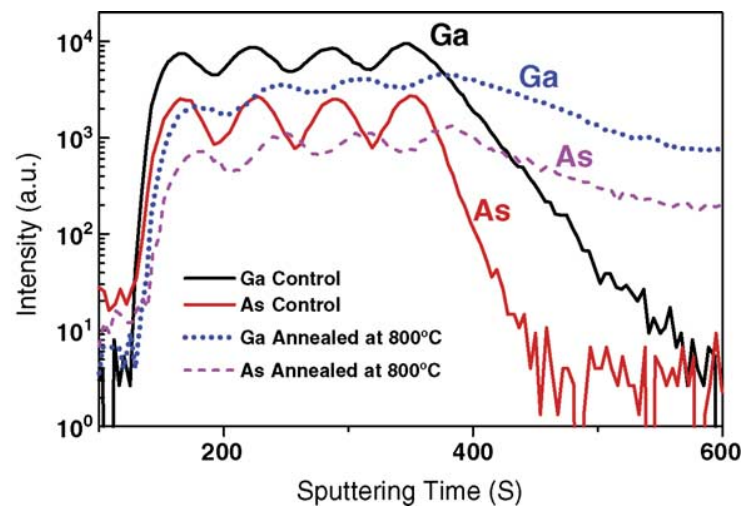

Fig. 4. SIMS characterization of control sample and sample treated by IFVD. 


\subsection{The effect on the combination between cladding layer and dielectric covered layer}

In order to find the effects on the combination of cladding layer and dielectric covered layer, two cladding structure samples were performed in the PL measurement. One of them is the InP cladding structure, the other is the InGaAs cladding layer. All the structures for the MQWs are the same except for the top cladding layer. Keeping the same experimental condition for these two kinds of samples, the band gap blue shift caused by different dielectric covered layers of $\mathrm{Si}_{3} \mathrm{~N}_{4}$ and $\mathrm{SiO}_{2}$ was measured. The results of band gap blue shifts can be observed that the blue shift of the combination of $\mathrm{InP}$ and $\mathrm{Si}_{3} \mathrm{~N}_{4}$ reached $30 \mathrm{meV}$ at $850{ }^{\circ} \mathrm{C}$; however, the blue shift for the combination of $\mathrm{InP}$ and $\mathrm{SiO}_{2}$ is only $25 \mathrm{meV}$. On the other hand, the combination of InGaAs with $\mathrm{SiO}_{2}$ covered layer creates $43 \mathrm{meV}$, but the combination of InGaAs with $\mathrm{Si}_{3} \mathrm{~N}_{4}$ covered layer can only reach $20 \mathrm{meV}$. Therefore, the combination of cladding layer and dielectric layer also affects the band gap tailing.

\section{Conclusion}

Summarizing the results of photoluminescence and SIMS characterization above for the three kinds of samples, the following conclusion can be drawn:

1. The band gap of quantum well structure of InGaAs/InP can be tailed by IFVD at certain conditions.

2. The blue shift of the band gap of InGaAs/InP structure depends on the dielectric layers, such as $\mathrm{SiO}_{2}, \mathrm{Si}_{3} \mathrm{~N}_{4}$, SOG, and annealing condition.

3. The blue shift of the band gap of InGaAs/InP structure also depends on the combination between cladding layer and dielectric layer.

4. The biggest blue shift of $30 \mathrm{meV}$ can be reached with the combination of InP cladding layer and $\mathrm{Si}_{3} \mathrm{~N}_{4}$ dielectric covered layer annealed at $800{ }^{\circ} \mathrm{C}$ for $10 \mathrm{~s}$.

\section{Acknowledgements}

The authors would like to thank Dr. B. Robinson at McMaster University Canada for growing the samples. This project at Tianjin Normal University is partially supported by the Nature Science Foundation of China (NSFC) under the contract number of 60276013 . The work at National Taiwan University was supported by funds from National Science Council of Republic of China, NSC 93-2218-E002-011 and 93-2215-E-002-035.

\section{References}

[1] W.K. Choi, Appl. Phys. Lett. 86 (2005) 021108

[2] D.G. Kim, Appl. Phys. Lett. 86 (2005) 021108.

[3] H.S. Lim, IEEE Photonics Technol. Lett. 14 (2002) 594.

[4] S. Kakimoto, J. Appl. Phys. 92 (2002) 6403.

[5] K.S. Kim, Semicond. Sci. Technol. 15 (2000) 1005.

[6] J. Zhao, Y.C. Wang, Surf. Coat. Technol. 131 (2000) 340.

[7] H.-S. Kim, J.W. Park, D.K. Oh, K.R. Oh, S.J. Kim, I.-H. Choi, Semicond. Sci. Technol. 15 (2000) 1005.

[8] D. Hofstetter, B. Maisenhölder, H.P. Zappe, IEEE J. Sel. Top. Quantum Electron. 4 (1998) 794.

[9] J.H. Marsh, Semicond. Sci. Technol. 8 (1993) 1136.

[10] D. Gdeepe, N. Holonyak Jr., J. Appl. Phys. 64 (1988) R93.

[11] P.G. Piva, R.D. Goldberg, I.V. Mitchell, H. Chen, R.M. Feenstra, G.C. Weatherly, D.W. McComb, G.C. Aers, P.J. Poole, S. Charbonneau, Appl. Phys. Lett. 72 (1998) 1599.

[12] S.R. Andrew, J.H. Marsh, M.C. Holland, A.H. Kean, IEEE Photonics Technol. Lett. 4 (1992) 426.

[13] B.B. Elenkrig, D.A. Thompson, J.G. Simmons, D.M. Bruce, Yu. Si, Jie Zhao, J.D. Evans, I.M. Templeton, Appl. Phys. Lett. 65 (1994) 1239.

[14] M. Paquette, J. Beauvais, J. Beerens, P.J. Poole, S. Charbonneau, C.J. Miner, C. Blaauw, Appl. Phys. Lett. 71 (1997) 3749.

[15] J.H. Lee, S.K. Si, Y.B. Moon, E.J. Yoon, S.J. Kim, Electron. Lett. 33 (1997) 1179

[16] G. Li, S.J. Chua, S.J. Xu, X.C. Wang, A. Saher Helmy, Mao-Long. Ke, J.H. Marsh, Appl. Phys. Lett. 73 (1998) 3393.

[17] J.S. Yu, J.D. Song, Y.T. Lee, J. Appl. Phys. 92 (2002) 1386.

[18] S. O’Brien, J.R. Shealy, D.P. Bour, L. Elbaum, J.Y. Chi, Appl. Phys. Lett. 56 (1990) 1365.

[19] S. Burkner, M. Maier, E.C. Larkins, W. Rothemund, E.P. O'Reilly, J.D. Ralston, J. Electron. Mater. 24 (1995) 805.

[20] G. Li, S.J. Chua, J.H. Teng, W. Wang, Z.C. Feng, H. Huang, T Osipowicz, J. Vac. Sci. Technol., B 17 (1999) 1507.

[21] J.H. Teng, J.R. Dong, S.J. Chua, D.A. Thompson, B.J. Robinson, A.S.W. Lee, J. Hazell, I. Sproule, Mater. Sci. Semicond. Process. 4 (2001) 621 .

[22] F. Camacho, E.A. Avrutin, P. Cusumano, A.S. Helmy, A.C. Bryce, J.H. Marsh, IEEE Photonics Technol. Lett. 9 (1997) 1208.

[23] W.J. Choi, S.M. Han, S.I. Shah, S.G. Choi, D.H. Woo, S. Lee, S.H. Kim, J.I. Lee, K.N. Kang, J. Cho, IEEE J. Sel. Top. Quantum Electron. 4 (1998) 624.

[24] N. Shimada, Y. Fukumoto, M. Uemukai, T. Suhara, H. Nishihara, A. Larsson, Jpn. J. Appl. Phys. 39 (Part 1) (2000) 5914. 